\section{Intimismo entre humanos e animais em um zoológico na Amazônia (Belém - PA)}

DoI

http://dx.doi.org/10.11606/ 2179-0892.ra.2020.168620
Flávio da Silveira

Universidade Federal do Pará / Belém, PA, Brasi flabreu@ufpa.br | https:/orcid.org/0000-0001-9421-5966

\section{Matheus Pereira Da Silva}

Universidade Federal do Pará / Belém, PA, Brasil

matheusk11@hotmail.com | https://orcid.org/0000-0002-7777-4675

RESUMO

O presente artigo parte de uma etnografia sobre as relações entre humanos e animais em um zoológico na Amazônia (Belém - PA), a partir das experiências interespecíficas diárias entre os profissionais nomeados tratadores e os animais cativos que constituem o acervo de espécies do pequeno zoo abrigado em seu interior. Através do acompanhamento das atividades diárias dos tratadores a título de alimentação, higienização dos viveiros e as motivações que orientam os cuidados diversos, problematizamos as negociações de sentido imputadas ao cumprimento de suas tarefas e ao estabelecimento de relações, engajamentos, estranhamentos e rupturas temporárias em seus laços, considerando as trocas de afetos e olhares que apontam para o que chamamos de intimismo em seus (des)encontros diários.

Intimism Between Humans and Animals in a Zoo in the Amazon - Belém (PA)

ABSTRACT The present article is based on an ethnography on the relationship between humans and animals in a zoo in the Amazon (Belém -PA), based on the daily interspecific experiences between the professionals named caretakers and the captive animals that constitute the collection of species of the small sheltered zoo inside. Through the monitoring of the daily activities of the caregivers as food, sanitation of the nurseries and motivations that guide various care, we problematize the negotiations of meaning attributed to the fulfillment of their tasks and to establish relationships, engagements, estrangement and temporary breaks in their ties, considering the exchanges of affections and looks that point to what we call intimism in their daily (dis) encounters

\section{KEYWORDS}

Keywords, Animals, Humans,

Intimism, Zoo, Amazon 


\section{ENCONTROS ENTRE ANIMAIS E HUMANOS NO BRAJBA}

O presente artigo' foi elaborado a partir de uma etnografia junto aos profissionais da Equipe da Fauna (biólogos, médicos veterinários e tratadores, que aqui enfocamos) e os animais que constituem a coleção natural do Bosque Rodrigues Alves - Jardim Botânico da Amazônia (BRAJBA), no período correspondente de agosto de 2011 até agosto de 2016.

O Bosque Rodrigues Alves é um patrimônio estadual (Silveira, 2014 e 2016) tombado por lei e é detentor de edificações que datam da chamada Belle Époque Paraense - a qual foi impulsionada pelo boom da borracha na virada do século XIX para o XX-, constituindo-se como um jardim botânico histórico inspirado no Bois de Bolougne, localizado na França. Nesse sentido, foi preservada parte da vegetação original existente na área de terra firme que abriga uma rica parcela da biodiversidade da Amazônia paraense.

No Bosque existem espécies vegetais ameaçadas de extinção, e algumas árvores com idade em torno dos 800 anos. Trata-se de um espaço verde que atualmente possui uma área total de 15 hectares $\left(151.867 \mathrm{~m}^{2}\right.$ ) distribuída em quatro quadrantes (Q I, Q II, Q III e Q IV) e 112 canteiros, contendo vegetação nativa de terra firme no contexto urbano. Os quadrantes possuem a mesma dimensão $\left(3.750 \mathrm{~m}^{2}\right)$ e apenas o quadrante QIV não é aberto ao público, sendo considerada área restrita com instalações da equipe da Fauna: a cozinha, onde se armazenam e preparam os alimentos; o Setor Extra, os animais que são encaminhados para Bosque passam por um período de adaptação em uma de suas salas sob estrita supervisão dos profissionais, o local abriga as espécies em três salas; a Quarentena, para as suas instalações são destinados os animais com problemas de saúde; e por fim as salas para armazenamento dos materiais de trabaIho e para planejamento de tratadores, biólogos e médicos veterinário.

A importância deste espaço verde no contexto urbano, em termos de conservação da biodiversidade amazônica está no fato de que ele apresenta um papel significativo para a preservação ex situ e in situ de espécies animais representativas da fauna neotropical. No primeiro caso, pela existência de um pequeno Jardim Zoológico com diversas espécies regionais ameaçadas de extinção - e que, geralmente são oriundas de doações de pessoas que não podem, ou não querem, mais criá-las em cativeiro - e, no segundo caso, por conter uma variedade de fauna nativa de vida livre e semi-livre que encontram no Bosque condições adequadas para a sua sobrevivência, constituindo, assim, parcela importante da fauna nativa urbana.

Os tratadores são responsáveis pelos cuidados diários com os animais. Eles contribuem com os programas de manejo, visando a saúde e o bem-estar animal, ao passo que os mantêm em exposição nos seus recintos e viveiros com diversos propósitos, como atividades educativas e o salvaguardo de sua vidas. O papel de um tratador também envolve muito trabalho físico, incluindo levantar, ajuntar e

\footnotetext{
1 | Gostaríamos de agradecer aos tratadores e demais funcionários do "Bosque" por nos permitirem a realização da pesquisa; ao CNPq pelo financiamento da pesquisa por meio do Projeto de Bolsa de Produtividade intitulado: "Estudo antropológico das interações de humanos com os não-humanos no Bosque Rodrigues Alves, na cidade de Belém (PA).Paisagens de evasão, conservação da biodiversidade e imaginário urbano"; e por fim, aos pareceristas anônimos da Revista de Antropologia pelas sugestões e revisão.
} 
carregar seus materiais de trabalho, bem como, esfregar e limpar os recintos, preparar alimentos e empurrar carrinhos de mão; e mesmo auxiliar na captura e restrição de animais para treinamento ou propósitos biomédicos. Os profissionais também interagem bastante com os visitantes, principalmente informando ou ensinando-os algo sobre os animais.

A passagem entre os gradeados que a priori "separam" os humanos dos animais é necessária ao exercício profissional dos tratadores (Estebanez, 2010), principalmente se consideramos as atividades técnicas e manejos cotidianos realizados diariamente. Tais relações no interior dos recintos conferem ao tratador um acesso privilegiado em relação ao animal, ao passo em que organizam um distanciamento relativo no ato de "guardar" o animal sob as dependências e proteções humanas visto que ainda no zoológico, o animal deve permanecer em suas paisagens e instalações sob observação constante dos trabalhadores da Equipe da Fauna.

No total são cinco tratadores: Elinaldo, Gelson, Moisés, Paulo Vitor e Salomão, que se organizam e dividem suas tarefas no local, porém nos finais de semana o plantão dos profissionais conta com três tratadores que se revezam nos afazeres estabelecidos, por isso todos devem saber realizar as atividades em todos os setores, como preparar a alimentação ou limpar os recintos. Os tratadores Elinaldo e Gelson ficavam responsáveis pela limpeza dos viveiros e o serviço da alimentação ao longo do Bosque; Paulo Vitor limpava e servia a alimentação para os animais na Quarentena e Setor Extra. Já, Moisés, ia buscar o capim-gordura, principal alimento para o peixe-boi, junto a outros trabalhadores em um veículo, sobretudo nas terçasfeiras e servia a alimentação para os animais. Por último, Salomão administrava os afazeres na cozinha e preparava os alimentos a serem servidos.

Os tratadores entram nos recintos e viveiros diariamente e, por isso, estabelecem uma relação mais estreita com os animais em cativeiro, o que exige maiores responsabilidades no que concerne aos cuidados diários com a vida das espécies em confinamento. Por ser uma profissão que atua diretamente com animais "selvagens", ao acompanharmos os tratadores foi possível perceber as dificuldades/periculosidades relacionadas aos contatos, bem como as trocas de afetos, a dedicação e a responsabilidade para com os animais que nutrem suas afinidades tecidas ao longo dos anos. Não raro foi possível ver junto ao público os tratadores entrarem nos recintos e realizarem gestos afetuosos nos animais. São comuns carinhos realizados na arara-azul Duda², no quati Weslley, ou na jaguatirica Nina, por exemplo.

Ao longo dos diálogos os tratadores contaram diversos acontecimentos envolvendo acidentes em seus encontros e visitações, relacionados a estranhamentos e ataques de animais no interior dos recintos. Em outras ocasiões foi possível acompanhar alguns episódios dessas tensões, como na entrada do tratador Paulo Vítor no viveiro dos papagaios-jandaias, quando as aves o atacaram agarrando-se em suas
2 | Os animais no Bosque têm seus nomes atribuídos pelos profissionais da Equipe da Fauna e se relacionam as suas afinidades e proximidades. Por certo os nomes integram a história de vida de cada animal, onde é possível narrar suas vidas através de suas ações, comportamentos e acontecimentos que os envolvam. Por ser um tema complexo iremos tratar de maneira mais adequada em um trabalho posterior. 
costas; noutra situação as aves o feriram em um dedo. Dessa forma, o cotidiano de encontros entre tratadores e animais é aberto às vicissitudes do encontro, podendose, não raro, ter que lidar com o inesperado durante seus manejos nos recintos.

Por isso os tratadores adotam medidas e cuidados para entrarem nos espaços destinados aos animais. É preciso sempre observar com atenção as condições e posição que os animais se encontram nos recintos e/ou viveiros, de forma que os animais também observam atentamente os profissionais. Considerando tais trocas de olhares, acompanhávamos como aconteciam tais encontros, os gestos técnicos, movimentos e toques em suas interações de manejo, que por vezes se desdobravam em estranhamentos nos laços entre humanos e animais.

Desta maneira, nos detemos nestes laços que remetem aos seus encontros cotidianos, atravessados por tensões, e que temos problematizado através de uma ferramenta conceitual que temos chamado de intimismo entre tratadores e animais (Silva, 2017; Silveira \& Silva, 2015a e 2015b) - já que havíamos brevemente esboçado a questão em trabalhos anteriores, constituindo-se assim como um work in progress - que aborda esta dimensão de relações de trocas de olhares que se desdobram em afetos, afinidades, estranhamentos e rupturas temporárias nos laços entre tratadores e animais em seus encontros.

As problemáticas em torno da ótica dos tratadores remetem a uma reflexão sobre as trocas de olhares entre humanos e animais no zoo, sobretudo ao olhar animal, o que nos leva à pergunta-título do famoso ensaio do inglês John Berger "Why look at animals?" (2009), quando o autor refere que os animais exibidos aos olhares humanos nos zoológicos expressariam historicamente ${ }^{3}$ as relações entre humanos e animais na cultura capitalista (Berger, 2009: 24).

Os desejos humanos de ver os animais movem o zoo, por isso ele mediaria as relações visuais entre humanos e animais, pois o conjunto de animais expostos à visitação não faz parte da vida imediata das pessoas, sendo assim a configuração de sua arquitetura contribuiria para a construção do "selvagem" em cena na zoo (Baratay \& Hadouin-Fourgier, 2002; Berger, 2009; Hodak, 1999; Marvin, 2008).

Ao visitarem o zoológico, humanos tendem a olhar os animais de forma a reconhecê-los como "familiares" em seu ambiente no zoo, ao passo que sua mirada se relaciona com os diversos saberes configurados historicamente acerca das espécies e o suposto abismo que as diferencia do sapiens. Assim, John Berger faz uma breve crítica às obras e pensamentos artísticos, filosóficos, entre outros, comentando as exibições e representações metafóricas dos seres "naturais" que tendem a se tornar invisíveis ao olhar humano, diante a superexibição ${ }^{5}$ e clarividência técnica de câmeras, telescópios, entre outros aparelhos. "Os animais são sempre os observados", continua Berger (2009:14), atestando que "o fato de que podem nos observar perdeu significado", e que quanto mais os conhecemos mais nos distanciamos deles movendo as fronteiras entre humanos e animais.
3 | Jean Estebanez (2008) apresenta como características dos zoológicos modernos a possibilidade de "ver todo o conteúdo" do espaço delimitado (os animais figurando na paisagem do recinto em questão) A espacialidade do lugar enquanto uma miniatura essencialmente "exótica" do mundo. A noção de exotismo estaria marcada pelas relações de poder inerentes ao olhar colonizador, historicamente situado, na construção da alteridade, como indicam as noções de "selvagem", "primitivo", "animal", por exemplo.

4| O antropólogo inglês Garry Marvin em seu artigo "L'animal de zoo. Un role entre sauvage et domestique (2008)" discorre sobre as configurações espaciais e arquitetônicas que agenciam a criação das representações coletivas, o animal "selvagem" em oposição ao "doméstico", e se efetivam através da teatralização que envolve o "espectador" (humano) e os "atores" (animais), organizando-se no complexo distanciamento relativo ao ato de "guardar" o animal sob as dependências e proteções humanas.

5| Ralph Acampora (2005) em um artigo escreve sobre as relações paradoxais entre os zoológicos modernos e a pornografia, na medida em que os humanos invisibilizam a natureza dos animais no zoo por exposição excessiva. Os animais são degradados e marginalizados através do marketing e do consumo de seus pontos de vista sob o ideal da preservação da natureza. Além disso, o autor trata da situação dos animais em cativeiro, quando tece uma crítica (de matriz 
Em relação aos tratadores, as experiências de trocas de olhares são fundamentais para tecerem relações com os animais, e claro, à execução de suas tarefas, quando notamos que ocorre a inversão de suas posições enquanto observadores e observados. Dessa forma, sobretudo os eventos de ataques e estranhamentos radicalizariam a experiência de exibição em seus encontros, quando humanos e animais participam das mudanças e inversões de papéis no ato mesmo de observarem-se reciprocamente, para adotarem a posição do outro enquanto observadores no jogo relacional.

Todos os cativos e tratadores participam dos jogos que emergem na vida social do zoo já que os tratadores ao entrarem nos recintos redobram sua atenção, situando-se nos mesmos através da troca de olhares necessária na interação, destacandose, sobretudo, as condições de entrada e contraponto nos recintos, incluindo gestos, posturas, expressões faciais, odores e sons. Então, é a partir das trocas de olhares que pensamos o intimismo e que discutiremos a seguir as formas como animais e humanos se afetam em seus encontros, quando os primeiros agem de maneira inesperada, conforme as expectativas que os profissionais têm quanto às ações que realizam e o comportamento do animal para se abrirem a um estranhamento processual que envolve afetos, gestos e toques entre si.

\section{TROCAS DE OLHARES ENTRE ANIMAIS E HUMANOS NO ZOO}

Todas as manhãs os tratadores chegam ao Bosque por volta das sete horas e logo caminham em direção ao Setor da Fauna, às suas dependências. Ali os profissionais se reúnem, organizam suas atividades diárias e distribuem as tarefas entre si. As atividades diárias fundamentais são organizadas em torno de três eixos de manejo e tarefas em relação aos animais: a observação do comportamento animal é realizada considerando-se a espécie e história de cada indivíduo; a higienização dos recintos e o preparo e distribuição dos alimentos.

Durante o inicio de cada manhã dois tratadores são responsáveis por realizarem visitas e observações em todos os recintos e viveiros, com objetivo de verificar o estado de saúde e o comportamento de cada individuo. A tarefa é denominada pelos tratadores de "rondas diárias", quando buscam observar traços do comportamento animal, suas movimentações e atividades nos recintos. Segundo Elinaldo, os tratadores observam "o comportamento de cada bicho". Tais observações são repassadas aos biólogos e médicos veterinários, que decidirão sobre o manejo e os procedimentos a serem tomados caso observem movimentações e atividades atípicas no interior da jaula.

O olhar que o tratador lança ao animal relaciona-se diretamente às intervenções sobre o seu corpo, quando pousa sobre ele uma atenção voltada aos seus cuidados e manejo, que contribuem para o bem-estar do espécime dentro de uma lógica de regramentos objetivando a conservação da espécie. Ou seja, a partir de tal olhar e conhecimento é possível ver/dizer algo sobre o comportamento animal, bem como foucaultiana) através do conceito de "zoöpticon" (2005: 78), como uma ilha de poder no arquipélago das instituições sociais hegemônicas mapeadas por Foucault. Dessa forma, o zoológico se relaciona com modos opressivos e produtivos em relação às práticas de espectadores de animais não humanos e da convivialidade entre espécies 
regular a fisiologia do seu corpo com a administração de suplementos vitamínicos e remédios, ou estabelecer parâmetros que constituam sua saúde e bem-estar.

Tais questões sobre a importância do olhar atento dos tratadores visando à entrada nos recintos, ficaram mais claras quando conversamos com Moisés enquanto servia a alimentação para o peixe-boi Kajuru, que é composta, sobretudo, por pedaços cozidos de batata-doce, capim-gordura, e frutas como manga (sua fruta favorita) e melancia. O profissional entrou no recinto conduzindo o carrinho-demão contendo alimentos quando vários visitantes se aproximaram para ver o animal receber o repasto, especialmente quando subia à superfície para comer. As pessoas aproveitavam para fotografá-lo, enquanto o tratador retirava os restos de capim-gordura e gal hos que caíam no lago onde vive o peixe. O animal é considerado o símbolo do Bosque, sendo o seu recinto o mais procurado pelos visitantes, segundo afirmam os trabalhadores do lugar. Após a retirada dos restos de alimentos, conversamos ainda no viveiro sobre suas entradas nos viveiros e a relação visual estabelecida com o sirênio, quando contou:

\footnotetext{
Então, a primeira coisa quando a gente entra no viveiro é verificar como o animal tá. Tá bem? Tá esperto? Tá arisco? Se ele tá mofino, ele tá quieto? Ele tá no chão? Sendo encontrado no chão, se você vê uma ave no chão existe algum problema que tem que ser revisto, tem alguma coisa errada aí. A gente verifica porque tá no chão, o que tá acontecendo, e aí depois que a gente faz essa primeira ronda, esse aparato visual, nós entramos no viveiro pra poder fazer a limpeza, retirar restos de alimentos, voltar a colocar alimentos. Cada animal tem um cuidado específico.
}

O "aparato visual" possibilita que o tratador se aproxime e interaja com o animal no interior do recinto, o que exige uma atenção frequente para se evitar "descuidos" e acidentes no local, pois "cada animal tem um cuidado específico". Já as entradas nos recintos de animais que são considerados "mais agressivos" "e "agitados" segundo Paulo Vitor, como a jaguatirica, macacos-prego ou tucanos, costumam ocorrer com cautela e o necessário estabelecimento de uma relação visual de (re)conhecimento recíproco. O tratador analisa a posição do animal no recinto e observa, previamente, a melhor forma para estabelecer o contato a partir de movimentos e gestos técnicos, quando traz consigo equipamentos (pratos, remédios, varas, vassoura, entre outros utensílios) de acordo com a tarefa que executará no local. É preciso deixar claro, que mesmo os menores movimentos podem configurar uma ameaça para a percepção animal, colocando tanto a vida do tratador quanto a do animal em risco.

Por outro lado, os riscos enfrentados pelos tratadores advêm de seu acesso diferenciado em relação a outros humanos, especialmente quanto aos animais que habitam o recinto visitado. Em conversa com Moisés sobre os cuidados adotados contou-nos o seguinte: 
Existe uma série de cuidados ao entrar no recinto dependendo dos animais, quando a gente tem que lidar com animais mais agressivos, menos agressivos. É muito relativo, por exemplo. Todos os viveiros do Bosque tiveram seus cambeamentos restaurados, uma coisa que nós não tínhamos há dois, três anos atrás. Então, o risco antigamente de fuga era muito maior do que hoje, não que não haja risco de fuga, mas hoje a coisa já mudou devido aos cambeamentos. A gente consegue entrar numa antessala dentro do viveiro e deixar o animal preso no próprio viveiro dele, aí depois nós podemos fechar a porta, abrir outra... Isso nos dá uma segurança maior.

A arquitetura do recinto separa animais e humanos e estabelece um distanciamento que possibilita maior segurança para os tratadores com instalações especificas e adaptadas para cada espécie, como a área de cambeamento e contenção dentro do viveiro, como observadas no recinto dos macacos-prego, por exemplo. Os riscos de fuga são contingenciados pelo restauro das instalações do recinto, mas os animais resistem e reagem de forma ativa ao seu cativeiro mesmo em espaços montados e controlados e vez ou outra escapam, como foi descrito em outro artigo um episódio da fuga de um macaco-prego no local (Pereira da Silva, 2019).

Ainda na mesma conversa o tratador Moisés apontou que os equipamentos de segurança são fundamentais no cotidiano de trabalho evitando que ocorram acidentes, ataques ou ferimentos entre ambos. Moisés comentou sobre a periculosidade de seus contatos e os cuidados adotados, como segue:

\footnotetext{
O correto é não entrar nos viveiros dos pássaros sem equipamentos de segurança, sem óculos, sem luvas, até para evitar um acidente com o próprio animal. Entrando sem equipamento de segurança, em um eventual ataque, geralmente, ele usa o braço para se defender, o animal pode vir a se machucar. E, geralmente, se machuca. Então, já com o de segurança não, seria mais tranquilo, é mais seguro e consegue se inverter a situação do ataque. Claro, com animais mais agressivos. As nossas araras vermelhas são bem agressivas, territoriais. Os periquitos, se um passar para o cambeamento do outro eles podem vir a se estranhar, então, é algo que a gente também evita. Não passe para o cambeamento do outro. Apesar de eles serem bem dóceis, eles podem se tornar agressivos, entre eles mesmos. A gente tem esse cuidado.
}

Aqui atentamos para o fato de que além dos equipamentos de segurança, o tratador falou sobre a experiência de estranhamento com os animais, nos apresentando a ideia de que os animais tornam-se agressivos de acordo com a forma com que ocorrem seus contatos e interações com o tratador e outros indivíduos da mesma espécie. Dessa forma, os cuidados no intercurso dos laços são baseados, sobretudo, no olhar e na percepção do tratador, sendo um traço fundamental na formação de seus conhecimentos acerca dos comportamentos animais e, a partir daí, no exercício de técnicas e táticas para a efetivação de ações que visem o bem-estar animal 
(Dawkins, 2004). Diante das vicissitudes enfrentadas no local, a exemplo do estresse sofrido por alguns animais como peixe-boi e macacos-prego devido aos tamanhos inapropriados dos recintos, estes últimos chegam a atirar seus alimentos em direção aos visitantes como bananas.

Certa vez enquanto realizavam a distribuição da comida no recinto dos tucanos - conhecidos por serem bastante agressivos e, tendo inclusive ferido um tratador na cabeça - o tratador arrumou o carrinho ao lado do recinto e abriu o cadeado a fim de ultrapassarmos o primeiro portão. Em seguida abriu o portão da gaiola das aves e, habilmente entrou no recinto para alimentá-las. Uma delas se aproximou, mas rapidamente percebendo o movimento de suas asas acelerou seus passos e saiu enquanto outra voava em direção ao portão. Continuamos acompanhando Moisés pelo Bosque e conversamos sobre as tensões experimentadas ao entrar nos recintos. Disse que "nem sempre a ave está estressada. Mas há dias que é complicado". Ficamos em silêncio, pois chegamos ao viveiro dos macacos-prego, e normalmente não conversamos no momento em que realizam suas atividades em certos recintos, pois a entrada e o intercurso de socialidades demandam maior atenção em suas atividades, como já dito. Após deixar a bandeja dos bichos na zona de cambeamento o tratador disse:

\footnotetext{
O animal, ele nos observa! Na verdade o animal, ele acaba se acostumando com a nossa presença. Como temos animais que são bem agressivos e ariscos, que mesmo depois de um tempo você cuidando deles, eles não abrem mão da agressividade deles. Você acaba conhecendo, sabendo como chegar perto, como não estressar o animal, mas ele, por si próprio, ele não abre mão desse lado dele complicado.
}

Os animais observam os tratadores quando se aproximam com seus instrumentos de trabalho para os seus contatos diários. As relações entre os conhecimentos e cuidados dos tratadores com os animais ao entrarem no recinto são realizadas, inicialmente, pelas trocas de olhares com os animais, sempre considerando sua potencial agressividade, o "lado complicado", e por certo imprevisível dos movimentos e demais agências das diferentes espécies. Assim, é necessário a atenção do tratador e seu conhecimento dos movimentos e comportamentos dos animais que se acostumam ao tratador.

O tratador Paulo Vítor enquanto preparava a alimentação para os animais de porte maior (jaguatirica, jacarés, corujas) na cozinha, deixou claro a atenção com o animal para suas relações no recinto. Mencionou, ainda, sobre os aspectos multissensoriais da experiência interespécies que compartilham:

Quando a gente entra, a gente primeiro olha. Vê o animal primeiro! Vê se ele não está em ponto de ataque né, e olha, e entra tranquilamente, e vai limpando lentamente, que aí ele vai perceber. A comida, você não pode fazer muito barulho. Os visitantes não podem fazer muito barulho quando a gente tá dentro do recinto, que é pra ele não morder a gente. Ainda tem isso também. 
A cautela adotada pelo tratador leva em consideração o público que os assiste, as conversas, gestos e outros movimentos que possam afetar o animal a ponto de os atacarem. Com o tempo de trabalho é possível perceber os melhores momentos para realizarem algumas de suas tarefas, mesmo com a presença do público. O tratador contou que "se tiver muita gente dentro, nas laterais do recinto, o quê que acontece? A vítima pode ser nós, entendeu!? Mordem nós lá dentro. A gente evita o máximo possível, num horário, assim, intermediário". Além disso, alguns efeitos das atitudes e ações do público ao observarem as atividades dos tratadores com os animais estão diretamente ligadas aos ataques.

\footnotetext{
Se a gente entra um no viveiro com um fluxo de gente muito grande, muito agito, automaticamente o bicho já fica agressivo. A vítima pode ser eu lá dentro. Ele pode me morder. Tem que ficar em total silêncio. Total sigilo lá dentro, pra não acontecer nenhuma coisa grave. Uma confiança, aí vai ficar normal. Tem, por exemplo, aqui a arara azul. Elas são muito delicadas, a arara azul. Muito. Tem esses bichos, assim, que são muito carinhosos, entendeu, com a gente. Então, são essas coisas.
}

Nas narrativas acima se percebe que os agentes têm seus movimentos entrelaçados, o menor gesto ou movimento do tratador ou do animal pode se desdobrar num ataque, conflito ou outros contatos relativamente perigosos. $\mathrm{O}$ "lado complicado", e/ou o "ponto de ataque", como aparece nas narrativas acima apontam para uma relação que inclui um estranhamento dos aspectos conhecidos do animal, seu comportamento e outras agências no zoo por meio

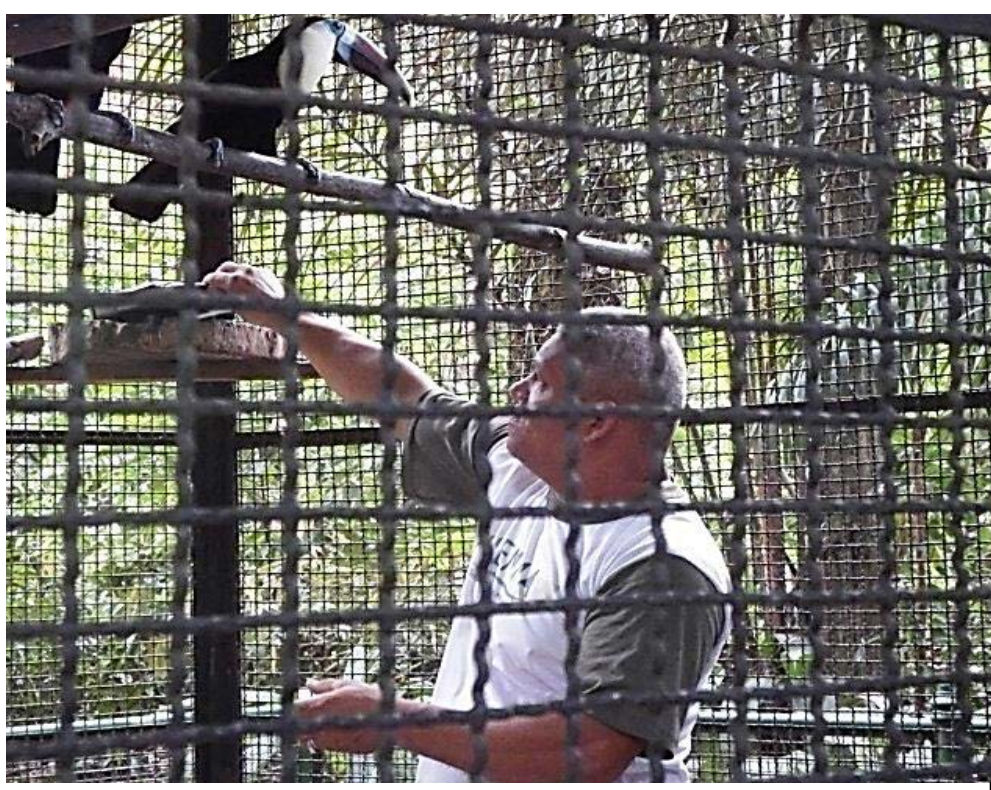
do compartilhamento de suas vidas no cotidiano.

A temporalidade e as afinidades, que trataremos a seguir, nutridas em seus laços não implica, necessariamente, num conhecimento por parte do tratador sobre o animal que o permita saber de antemão quais serão seus movimentos, comportamentos ou ações no recinto. Por isso, os tratadores se colocam à espreita junto aos animais, buscando observar suas posições e movimentos com uma atenção à saúde, ao bem-estar animal e às condições no viveiro - imprescindíveis para os contatos e proximidades com os animais, a fim de evitar problemas entre os agentes. 


\section{AFINIDADES PARCIAIS E PRÁTICAS DE DOMESTICAÇÃo NO ZOO}

Vincianne Despret (2013 b) trata das diferentes maneiras que os corpos dos etólogos estão ativamente engajados quando interagem com os animais que observam em campo. A autora enfoca os aspectos práticos da objetividade do conhecimento e, a partir daí a importância da construção de afinidades trabalhadas em seus encontros diários. Sendo assim, as afinidades são efetuadas ao longo do tempo de maneira parcial, curiosa e responsiva em suas companhias (Despret, 2013b: 9), uma vez que a objetividade do conhecimento dos cientistas não buscaria ver ou sentir como um animal e, sim, tornar o corpo disponível para ser afetado pela resposta do outro, diante das relações entre eles. Tais experiências entre os agentes é o efeito de sua convivialidade, envolvendo anos de observações cuidadosas, de trabalho e de compartilhamento de suas vidas.

De modo análogo, para os tratadores a construção de afinidades é um aspecto crucial em seu trabalho para a realização de seus cuidados e emerge nas interações, comunicação e contatos ao longo de seus anos de trabalho e afetuosidade em seus laços. Por isso, a importância do gesto de tocar apresenta um possível estreitamento dos vínculos afetivos, ou uma relação especial com os animais (Estebanez, 2010), pois é na proximidade afetiva de tocar e ser tocado que primeiro se percebe a coexistência e os cuidados na vida diária dos animais. Em uma situação na alimentação matutina, Gelson realizava carícias ao levar uma banana até o quati Weslley que a agarrava e recebia carinhos em um momento afetivo.

Os gestos conferidos por Celson aludem a um "certo modo" de tocar o animal (Estebanez, 2010) propício a uma negociação de sentidos para a realização de sua tarefa. Noutro momento, ao rememorar sobre um peixe pirarucu do zoo que faleceu, disse: "Aí, até hoje a gente lembra dele porque a gente se apegou ao animal!". O "apego" se dá através de suas afinidades experimentado na interação com o animal e permeado por ambiguidades.

Durante uma caminhada com Moisés, conversamos sobre a "faca de dois gumes", segundo o tratador, que envolve o relacionamento de proximidade com o animal. Para Moisés, é preciso considerar os aspectos danosos relativos ao "costume" do animal com a presença de um tratador em especial, ou com humanos quando

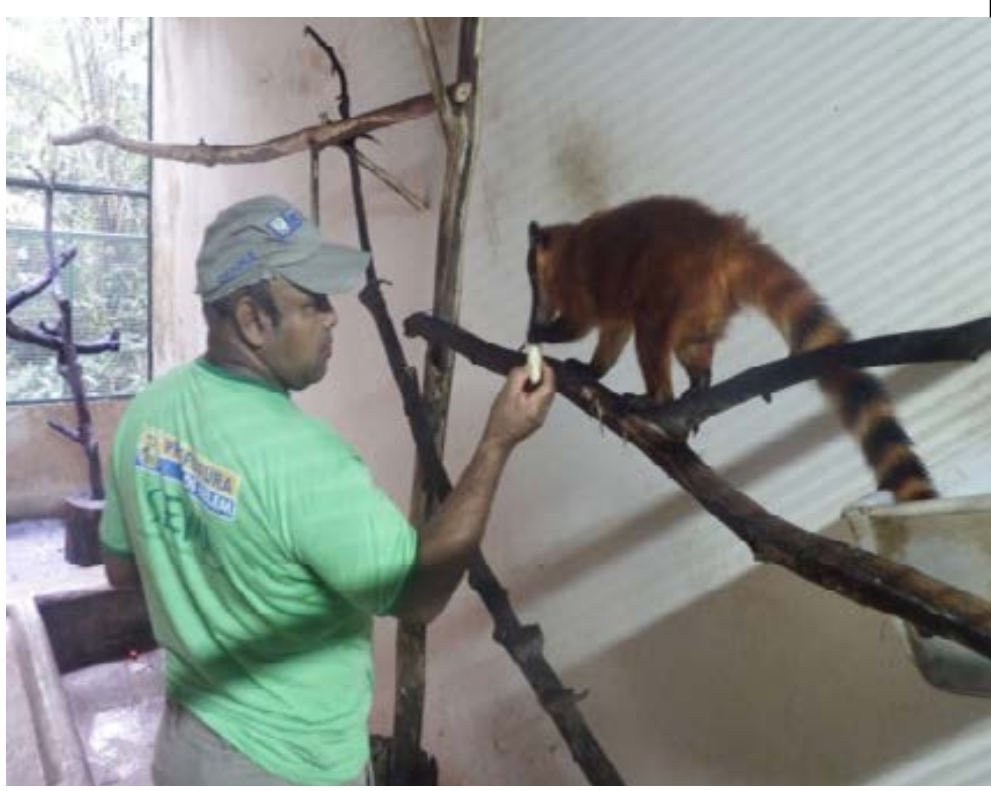


ele é oriundo de situações de abandono ou doações. Ele narrou a história de uma arara-vermelha que foi doada e que teve sérios problemas de adaptação à vida em cativeiro, bem como a rotina no recinto, o que ocasionou rejeição à comida, por exemplo. Mesmo após o acompanhamento de veterinários foi necessário o contato com o doador para que ela se alimentasse adequadamente. Quanto ao vínculo do animal com o tratador existem fatores que contribuem para a ambiguidade nas relações com os animais:

\footnotetext{
Existem dois fatores predominantes pra isso: o primeiro é... Que quando o animal não se apega a alguém, ele teme, então, quando ele temer, ele geralmente não ataca! Então, isso dá uma segurança para o tratador porque quando o animal se acostuma com a pessoa ele cria confiança até mesmo para se gerar um ataque. Outro fator que a gente leva em consideração é o fato de que hoje você está no, no, no local de trabalho, e amanhã você pode não estar.
}

O receio gerado pelo apego animal em relação ao humano se relaciona com o estreitamento dos laços afetivos, quando os tratadores e os animais compartilham sua confiança e interesse ao se engajarem ativamente no jogo proposto, de dar atenção intensa aos mínimos gestos que expressam desejos, expectativas e afetos, e de responder-Ihes no cotidiano. Os tratadores experimentam afetos e dificuldades ante suas atitudes e práticas de manejo em relação aos animais, pois deve se levar em consideração o ponto de vista do animal, suas proximidades e distanciamentos afetivos no trato diário para que não teçam relações danosas entre si. Cuidados que também possibilitam ao tratador situar-se no recinto e posicionar-se quanto ao contato com o animal em questão.

Tais afinidades evocam uma dimensão ética e pragmática no cuidado com os animais em torno de seus distanciamentos e proximidades afetivas. Ficou evidente que os tratadores questionam suas proximidades afetivas com os animais em relação aos sofrimentos compartilhados e outros problemas envolvidos em suas vidas diárias. A proximidade sempre está relacionada a um limite de contato, de interação e gestos entre ambos, de acordo com a singularidade do animal envolvido. Os macacos-prego não permitem interações de contato físico direto em qualquer situação. Já a arara-azul e uma vermelha permitem toques, carinhos e interação de alimentação direta. Moisés esboçou seu posicionamento quanto aos traços do comportamento animal, troca de afetos e essa dimensão ética dos cuidados:

\footnotetext{
Então, a gente percebe que o trabalho tá sendo bem feito quando esse animal, ele mantêm esse nível de agressividade, ele tem o respeito pela gente, claramente ele respeita, essa relação de tratador e animal mesmo, essa relação de respeito que a gente tem com o animal, de tratar bem, mas a gente sabe que ele particularmente não pode nos amar, porque no dia que nós não estivermos aqui quem vai sofrer é eles. Então, a gente tem essa orientação de não
} 
passar tanto a mão na cabeça, não botar tanto no colo, a gente percebe que o animal foi bem tratado quando ele não sente a nossa falta mais, aí a gente fez o trabalho correto. Quando o animal começa a sofrer por causa disso, a gente vê que a gente tá errando no tratamento, isso não é legal é ruim, porque o animal diferentemente do humano, ele é muito frágil em relação a isso quando ele se apega, quando ele se adapta ele se desapegar é muito ruim.

Diante a miríade de afetos envolvidos entre tratadores e animais, Moisés abordou a proximidade do tratador no relacionamento com o animal e que o bom trabalho é percebido quando os animais mantem a agressividade criando uma distância simbólica-afetiva para que não sinta falta do tratador com quem o animal possui laços estreitos ou não, caso este não esteja no zoo.

Assim, são imprescindíveis a atenção e o olhar do tratador em relação aos seus próprios laços com os animais, pois as afinidades dos tratadores - o amor relacionado ao apego - pode apresentar desdobramentos prejudiciais para o animal cativo, que tende a sofrer mais no distanciamento em relação ao humano por alguma eventualidade. É certo que os tratadores também sofrem com a distância, ou a morte de algum animal-o caso do pirarucu que veio a óbito -, pois é na interação com o animal que ocorrem as trocas de afetos, o que problematiza as recomendações de não amar os animais, referidas anteriormente.

"Então, por outro lado a gente tem a orientação de não gerar muita... de não ficar íntimo do animal", disse Moisés noutro dia, aludindo suas orientações para não estabeleceram laços profundos com os animais. Certa vez mencionou na recepção do Chalé de Ferro, local onde fica a administração do parque, que o tratador tinha "uma relação intimista com os animais". E o tratador continuou falando sobre os problemas de seus laços com os animais, pois também havia riscos em suas relações e companhias. Aqui é necessário atentar para o fato de que a própria agressividade opera um corte nas relações entre humanos e animais, daí a limitação quanto à intimidade nos seus laços.

Como já foi trabalhado em outro lugar (Silveira \& Silva, 2015), tais aspectos de intimidade per se concernem a uma interioridade psicológica, ou uma pessoalidade sentimental distinta e reservada em relação ao mundo "externo", que remetem a divisão entre eu e mundo, interior e exterior, quando o sujeito reage a estímulos exteriores e se constitui num sujeito psi com sua intimidade mais ou menos preservada, evocando, por isso, imagens do privado. Por outro lado, o intimismo (Silva, 2017; Silveira \& Silva, 2015) se relaciona à dimensão das afinidades e estranhamentos, que trataremos adiante, que se desdobram em afetuosidade e rupturas de seus laços no convívio envolvendo animais e humanos no zoo.

Dessa forma, pensávamos sobre o intimismo, suas afinidades e laços ao longo do tempo, visto que há animais que são trazidos em condição de filhotes, quando os tratadores cuidam de sua adaptação à vida animal no zoo, o que implica 
estreitamento e aprofundamento dos vínculos entre tratadores e animais. Os animais se acostumam e acostumam os tratadores a suas companhias, o que pode levar a ocorrências de alguns problemas para os animais, como disse Moisés, "porque a gente já teve caso aqui no Bosque da pessoa cuidar do animal desde pequeno, cuida, cuida, cuida, ah eu saio da Fauna, aí o animal não quer comer, adoece, se estressa, acontece uma série de questões".

Em outra conversa Moisés contou sobre a chegada de Duda ao local, bem como o desenvolvimento de sua vida no zoo:

\footnotetext{
Quando a arara azul chegou, que foi o Duda, quem recebeu ela fui eu. Então eu lembro que essa arara foi trazida por um militar, se eu não estou enganado da Aeronáutica, na época, e esse animal, ele deu muito trabalho pra se alimentar. Esse senhor teve que vir aqui várias vezes durante o mês pra que o Duda viesse a comer, porque ele não queria comer. Quer dizer a ave começa a definhar, começa a emagrecer, começa a adoecer e aí ele tinha que vir pra pegar nela, passar a mão, até ela se desacostumar foi um processo lento e complicado, foi difícil, até a ave se desacostumar foi difícil, hoje não, o Duda tá independente aí, independente entre aspas, que é um animal que nunca vai poder ser solto na natureza: não sabe caçar, não sabe se alimentar só por ter sido doméstico desde criança, é um animal que provavelmente não sobreviveria se fosse jogado em mata aberta, por conta disso, foi domesticado, tanto que a única ave aqui do parque que você pode pegar e ela não vai te causa nenhum dano, pega na cabeça dela, na asa sem problema nenhum, quando ela bica não bica forte o ser humano, ela só aperta e solta. Já as vermelhas não, as vermelhas só o fato de chegar perto, elas já vão pra cima, elas querem bicar, já querem ferir, já querem, quer dizer, é um animal que a gente ta conservando o máximo possível ali mesmo na questão doméstica, mas da maneira mais correta possível.
}

Duda, por ter um laço afetivo com seu antigo "dono" e estar habituada ao seu lar, sofreu com a mudança para o zoo, a presentando dificuldades na adaptação ao local. A fala de Moisés torna mais claro que nas relações entre tratadores e animais a confiança transmitida nos gestos e todo o envolvimento afetivo com os animais, desdobra-se numa experiência que faz existir novas identidades para humanos e animais a partir de sua convivialidade. Tais relações e afinidades indicam confiança, carinho, cuidado e afeto que conectam os agentes e revelam uma prática de domesticação, uma vez que a arara-azul passou por novas práticas de socialidade que incluíam um regime alimentar diferenciado, interações com outras ambiências, paisagens e pessoas, englobando um feixe de relações afetivas e ecológicas.

Tão logo esta prática propõe novas maneiras de se comportar, novas identidades, ela modifica os dois, tratadores e animais. Ambos transformam a prática que os articula através de uma prática de "antropo-zoo-gênese" (Despret, 2004), que constrói o animal e os humanos reciprocamente em formas diferentes, embora 


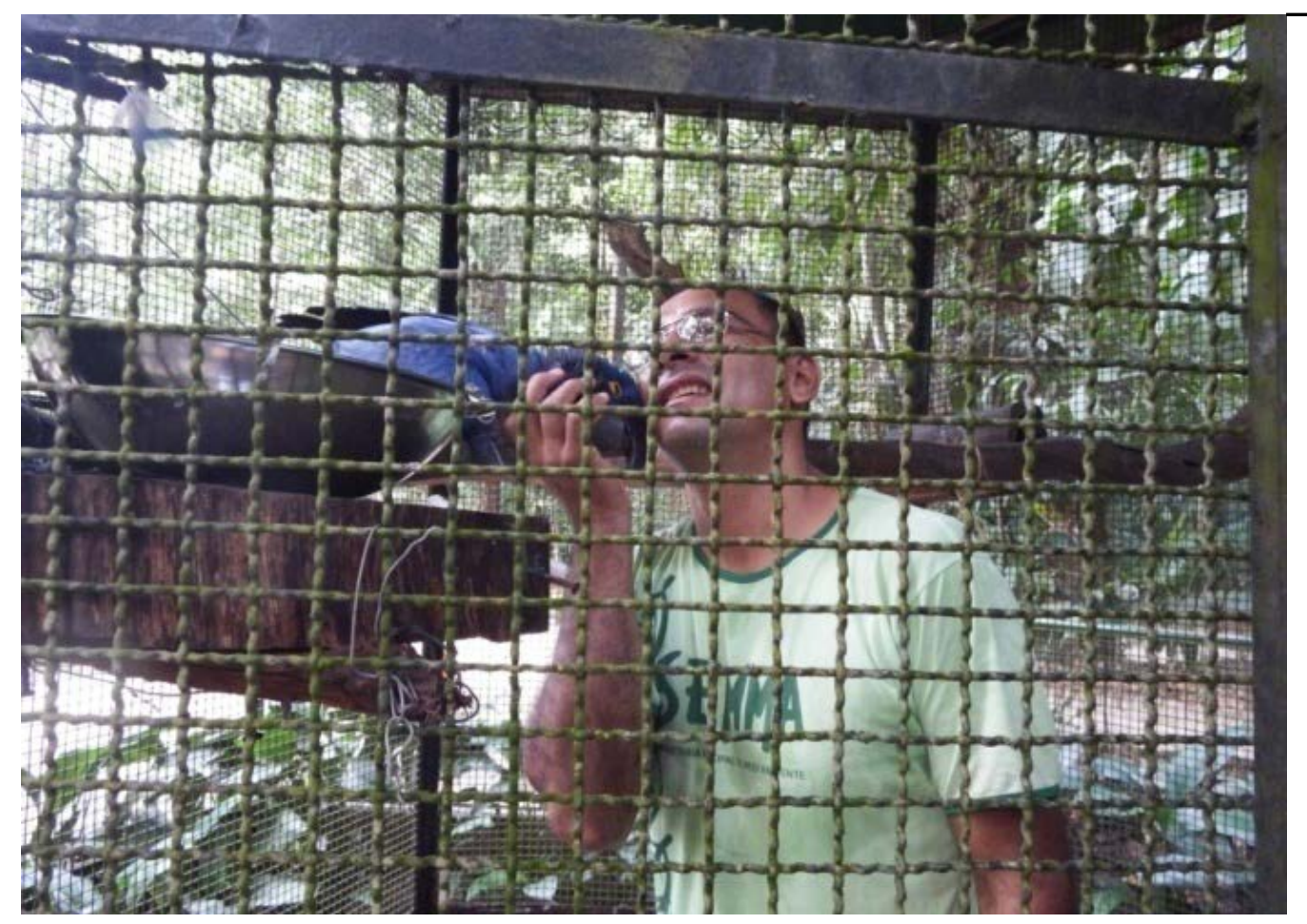

parcialmente sobrepostas. Tal dimensão relacional surge como uma possibilidade de adicionar significados novos ao estar com um animal, uma possibilidade de revelar novas formas de estar junto desempenhando um corpo com outra sensibilidade com o animal.

Esta confiança que conecta tratadores e animais produz oportunidades de novos (des)encontros e práticas de domesticação, o que não quer dizer que os animais tornam-se domésticos. Sobre a domesticação Digard (1988) discorre sobre o aspecto de sua não completude, quando a ação de domesticar é contínua, cotidiana e deve ser investida de forma que os animais podem se "desdomesticar" e retornar a um estado "selvagem". Dessa maneira o que se destaca, sobretudo nas relações entre tratadores e animais no zoo é tal aspecto aludido de domesticação com seu caráter fluído e parcial, em processos contínuos em suas relações no zoo.

Mesmo diante as práticas de domesticação, os comportamentos e atitudes dos animais em relação aos humanos não sugerem uma forma pacífica e constante em seus laços. Há situações em que ocorre uma ruptura temporária nos laços construídos, estranhamentos que distanciam e limitam seus laços e contatos, o que pode vir a gerar acidentes, ferimentos e outros problemas.

\section{ATAQUES E ESTRANHAMENTOS ANIMAIS NO BOSQUE}

Como apontamos, as visitas e os cuidados direcionados aos animais pelos tratadores têm como base o conhecimento dos comportamentos do e com animal em questão, durante as visitas aos viveiros e suas vicissitudes. Neles há condições e contrapontos
Figura 3

O tratador Elinaldo

e a arara-azul Duda.

Fonte: Matheus Pereira da Silva (2015) 
às suas passagens e alianças com os animais mais ou menos duradouras ante suas tarefas-quando ocorrem interações de toda ordem, gestos, toques e olhares ligados às experiências com os animais.

Mesmo diante a proximidade e os cuidados cotidianos em que os animais negociam e trocam afetos com os humanos, há (des)conexões parciais em seus relacionamentos que exploram os limites das relações entre humanos e animais, envolvendo a dimensão ética e afetiva entre ambos. O cotidiano de tratadores e animais assim é marcado pela imprevisibilidade em seus encontros, podendo ocorrer estranhamentos, ataques ou acidentes.

Nasprimeirasmanhãsaovisitarmosozoonãopercebemostaisacontecimentos, mas atentamos para a tensão que envolvia suas entradas nos viveiros, sobretudo no dos macacos-prego, quando os animais permaneciam agitados, se locomovendo pelos troncos de árvores e pelo gradeado do recinto sempre atentos ao menor gesto humano. Já os tratadores por sua vez tinham que redobrar a atenção com relação aos macacos, principalmente nos dias em que estavam estressados por algum motivo. Esta dimensão do imprevisível se mistura ao ambiente de afetos e medos que perpassam seus encontros onde há riscos e periculosidades para ambos.

Em uma manhã durante a disposição dos alimentos seguimos Elinaldo junto a seu carrinho com frutas, legumes e ração até o recinto das pequenas aves, as marianinhas, onde o acompanhamos até adentrar o local. Após caminhamos em direção à cozinha onde nos falou sobre as tensões que envolvem a sua entrada, as trocas de olhares que se sucedem, a periculosidade de sua profissão e a responsabilidade para com a vida do animal:

\footnotetext{
O senhor acha perigoso aí, seu Elinaldo, entrar no recinto?

Não. Nesses aqui, eu não acho perigoso. O mais perigoso são

o dos macacos. Esses aqui não são tão agressivos.

Os macacos são os mais perigosos...

Só vem aqui quem conhece, para entrar lá, fazer a manutenção.

Já teve algum acidente com os animais?

Só o... Assim, grave não, só o tucano lá, e a coruja que pulou na minha cabeça. O tuca-

no beliscou e a coruja fez assim! [O tratador gesticulou imitando o ataque da ave].
}

A atenção redobrada com os primatas é essencial para a interação no interior do recinto, principalmente quando é realizada a limpeza, pois exige um maior tempo de permanência no lugar. São quatro macacos-prego, e normalmente um tratador ou no máximo dois entram no lugar. Eles são rápidos e se tornam agressivos quando estressados nas jaulas. Como ficou claro na fala de Elinaldo, nem todos os animais são agressivos e perigosos, mas em relação às aves e aos mamíferos os tratadores podem se envolver em situações que possibilitam desencontros e tensões, pois ao 
entrar nos espaços de conservação ex situ precisam negociar o compartilhamento temporário na espacialidade do lugar com os animais que percebem suas delimitações como um território restritivo de existência.

Os perigos em relação aos animais são percebidos nas experiências de convívio ao longo do tempo. O tratador Salomão, o mais longevo na Equipe da Fauna (28 anos trabalhando no local, e que se aposentou em 2017), era o único que entrava no recinto dos macacos-prego sozinho. No decorrer dos anos os outros tratadores foram "aprendendo a observar o comportamento do animal", comentou Celson, sobre realizarem as entradas e atividades naquele recinto.

Os tratadores ao caminharem no recinto-território agenciam o seu lugar no espaço a partir das trocas de olhares, de toques e de interações diversas com o espécime em questão - necessitando formas distintas de proceder no trato -, o que remete a certas "negociações" em relação às agências animais, na medida em que ambos agentes adotam posturas e precauções no compartilhamento do espaço. "A gente entra com cautela né, com cuidado pra não ser mordido.", disse Paulo. Mesmo diante dos cuidados é possível que ocorra ataques dos animais aos humanos como contou Elinaldo.

Também foi possível acompanhar alguns episódios dessas tensões, como na entrada do tratador Paulo no viveiro dos papagaios-jandaias, quando o atacaram, se agarrando em suas costas. Certa manhã saímos do Setor da Fauna em direção aos recintos das aves acompanhando Gelson e Paulo para a distribuição dos alimentos. Inicialmente os tratadores alimentaram as araras-vermelhas, em seguida Duda, as marianinhas e as corujas. Os tratadores se dividiram em seguida, Gelson retornou ao Setor da Fauna atendendo um chamado de Moisés que contatou Paulo por celular, e seguimos acompanhando-o quando foi ao recinto dos papagaios-jandaia.

Ao entrar no recinto o tratador lentamente abriu o cadeado e observou a disposição das aves no local, algumas estavam no poleiro e outras no gradeado. Então, colocou a vasilha com o alimento para as aves no comedouro quando duas aves voaram em suas costas e ficaram agarradas na camisa. $O$ tratador rapidamente se sacudiu com as mãos para cima a fim de evitar atingi-las e nós apenas pudemos olhar pelo lado de fora, sem o menor movimento para não estressá-las, ou causar qualquer aborrecimento às aves.

Elas abandonaram as costas do tratador, que rapidamente conseguiu sair e fechar o recinto. Paulo apenas nos disse que as aves estavam "estressadas ultimamente", e isso dificultava o trabalho. Em outras ocasiões foi necessária a ajuda do tratador Célson, que pelo lado de fora do recinto chamava a atenção das aves assoviando e balançando o gradeado, enquanto o outro tratador entrava rapidamente, olhando para as aves, empunhando um puçáa ou sonar caso fosse necessário afastá-las.

A agressividade animal e seu estresse (portanto, o seu grau de periculosidade) e a sua sensação do medo, segundo Gelson, se relacionam com a experiência de

6| Puçá é um apetrecho confeccionado com rede e ensacador instalado em uma armação em forma de aro, usado na captura de animais 
estranhamento e pode estar associada à presença do público - ou do etnógrafo -, ao clima, ao tipo de recinto, entre outros fatores, compondo uma experiência multissensorial que a torna complexa.

Por vezes o estresse animal está associado, entre outros fatores, à própria localização do jardim zoológico, situado nas proximidades de uma avenida movimentada e ruidosa no bairro do Marco, além da inadequação dos espaços de confinamento pelo excesso de animais num mesmo recinto. Sendo assim, o conhecimento produzido nas trocas de olhares com os animais, associado à percepção de seus comportamentos está embasado em aspectos da própria experiência dos tratadores no transcorrer de suas agências ligadas aos manejos da fauna no zoo, contribuindo para as possibilidades de maximização do bem-estar animal em cativeiro e sua conservação já que muitas vezes não podem retornar aos seus habitats dado a degradação.

Sobre episódios ocorridos no Bosque ligados a ataques, estranhamentos e acidentes nas suas paisagens, Gelson relatou:

\footnotetext{
- E nesse tempo que o senhor trabalha aqui já houve algum problema envolvendo algum animal, como um ataque?

- Já, sim. Teve sim, uma vez eu tava lá no Coreto e tinha um gavião real, dois gaviões reais. Lá eu estava com eles aí um me atacou... Porque a gente entra, sempre bom prestar atenção né!? Eu falhei, falhei assim [...] mas depois fui ao médico, melhorei! Voltei e continuei fazendo meu serviço, não fiquei com medo.
}

Noutra visita conversamos com Moisés que falou sobre diversos acidentes e ataques envolvendo humanos e animais no zoo:

\footnotetext{
Uma vez eu tava tratando dum animal, um sagui que é um macaco bem pequeno, e... Para ele não fugir eu tive que segurá-lo, como não tive condições de segurar ele de maneira adequada, ele virou a cabeça e mordeu a minha mão, o dente dele cravou a minha mão todinha. Então, quer dizer, é o risco que a gente corre todo dia, ser mordido por macaco-prego, quati, ser atacado por um tucano, como já tiveram pessoas aqui, a própria bióloga já foi, já teve a cabeça furada por um tucano aqui dentro. O biólogo, também, e... Outras pessoas já tiveram vários ferimentos de papagaio... O papagaio vem e corta o dedo, então esses riscos são costumes, quer dizer, até serpentes que tem aqui: são jiboias, algumas pessoas já foram mordidas também pela jiboia (...) também, quando elas aparecem aqui no parque, na verdade nós temos jiboias, (...) nós temos jiboias, não em viveiros.
}

Os ataques apontam para um intimismo entre humanos e os animais que não apenas reagem, mas respondem abertamente à ação humana no viveiro, onde as esferas de vulnerabilidade de seus contatos e de atividade se sobrepõem e fazem destacar o seu co-envolvimento. Os animais oferecem "resistências" e "negociações" quanto às proximidades 
e contatos - não se trata de meras reações comportamentais "influenciadas" por um ambiente externo, pois humanos e animais se tornam agentes-companheiros (Despret, 2013a: 44) em seus (des)encontros, conflitos, colaborações, fricções e afinidades.

O que compreendemos como intimismo se relaciona com as trocas de olhares, afetos e estranhamentos entre humanos e animais, expressos e descritos esplendidamente no conto "O búfalo", de Clarice Lispector, escrito em 1956, e publicado pela primeira vez na Revista Senhor em 1960. Neste mesmo ano seria relançado como parte da coletânea Laços de família. A autora descreve uma mulher que caminha ao longo de um zoológico e, em sua angústia diante de uma crise conjugal, busca explorar na animalidade um aprendizado de ódio com os animais cativos. O episódio interespécies a torna disponível para ser emocionalmente afetada pelos encontros com os animais, especialmente mediante a permuta de olhares entre ela e o animal.

Dessa maneira, na escritura errante de Lispector (Nunes, 1989), sobretudo na geografia ficcional do zoo que se desenha, humanos e animais se apresentam como partes permutáveis e paradoxais de uma cena vasta e ilimitada da natureza compacta das coisas, o mundo em que o humano se situa e localiza sua existência (Nunes, 1989: 169).

Assim a personagem caminha ao longo do zoo lançando seu olhar para os animais nas jaulas. Os animais são descritos pela potência de seus olhares que desestabilizam o desejo de aprendizagem do ódio que motivava a mulher em sua deriva pelo lugar, em meio às jaulas. A estranheza da situação diante o despojamento do olhar animal a força a desviar sua visada, aonde o sentimento que "não viera buscar" emerge em sua ambivalência: amor, ódio, estranhamento de si com o animal outro (Nunes, 2007). A personagem é arrastada pela potência do olhar animal que desestabiliza seu corpo, friccionando-o, impelindo-o à fuga.

Então, a personagem recomeça a andar em direção aos demais bichos quando se depara com um quati dentro de sua jaula, e ambos se olham de forma que o olhar do animal perturba a personagem, forçando-a a desviar seu olhar, e devido sua proximidade com as grades, se sente enjaulada do outro lado do gradeado: "A jaula era sempre do lado onde ela estava: deu um gemido que pareceu vir da sola dos pés." (Lispector, 2013: 67). Com isso, em seu passeio pelo jardim, a mulher é afetada incessantemente pelo olhar animal e percebe seus olhares e movimentos, carregados de intenções, desejos e sentidos, em uma ordem da natureza compartilhada em suas diferenças com os humanos, invertendo seu estatuto de observadora humana e enjaulando-a em sua frágil humanidade domesticada.

Segue a desfilar o mundo das bestasjá que a mulhercaminha pelozoo até perceber o búfalo, distante em seu grande terreno seco e rodeado de grades altas. Ao se deparar com o búfalo a personagem se afeta a tal ponto com o olhar do animal que se sente "presa, enquanto escorregava enfeitiçada ao longo das grades. Em tão lenta vertigem que antes do corpo baquear macio a mulher viu o céu inteiro e um búfalo" (Lispector, 2013: 69). 
Desdobra-se daí o intimismo entre a personagem e o animal em uma mise-en-scène no zoo, quando trocam olhares e invertem suas posições de observador e observado, humanidade e animalidade. A personagem acolhe o olhar bovino e um aprendizado relativo às possibilidades de seu corpo ser afetado (Despret, 2004; Favret-Saada, 2005), quando um animal também nos olha e a partir daí desenvolve-se um potencial de alteridade significativo: o estranhamento na experiência com o olhar animal, que abala os limiares que dividem as esferas entre natureza e cultura no zoo.

\section{CONSIDERAÇõES FINAIS}

O intimismo entre humanos e animais problematiza as trocas de ol hares e a construção de afinidades e estranhamentos com as espécies-companheiras a partir de seus encontros, quando humanos e animais são convidados para outros modos de ser, a relacionamentos e novas maneiras de habitar mundos (Haraway, 2003 e 2008). Os agentes engajados no jogo relacional criam afinidades, movidas em seus encontros sempre negociadas, sendo o efeito de sua convivialidade ligada a anos de observações cuidadosas, de trabalho e de compartilhamento de suas vidas no zoo.

Animais e humanos criam seus entrelaçamentos a partir de afinidades parciais, mas essas não são criadas com o objetivo de sentir, conhecer ou ver como um animal. Não se trata de uma reflexão sobre alguma interioridade psicológica ou vida animal interior. Assim como os saberes localizados em Haraway (1988), o trabalho dos tratadores implica uma experimentação com o próprio corpo, considerando a companhia e o modo de vida animal, a partir de suas tarefas e manejo. O corpo cria ativamente afinidades parciais (Despret, 2013 b), aprende a conectar experiências à medida em que se torna disponível para ser afetado por outros corpos, o que seria a base da construção do conhecimento confiável dos tratadores, que envolve aprender a pensar com, e mediante, o corpo outro (Haraway, 1988).

Os afetos evocados aqui em certo sentido não se "passam" na cabeça, mente ou outra forma de interioridade da personagem do conto, ou mesmo dos tratadores, nem dizem respeito a sentimentos familiares, pessoais e subjetivos, mas referem-se àquilo que se passa no mundo e nas suas relações com os outros (Despret, 2011), pois implicam estratégias sociais quanto a aprender a ser afetado e a desenvolver uma sensibilidade aberta à animalidade em seus encontros.

Flávio Leonel Abreu da Silveira é Professor Associado II da Universidade Federal do Pará e docente do Programa de Pós-Graduação em Sociologia e Antropologia (PPCSA) 
Matheus Henrique Pereira da Silva é Mestrando do Programa de Pós-Graduação em Sociologia e Antropologia (PPCSA) da Universidade Federal do Pará

Contribuição de autoria: o artigo foi escrito pelos autores de modo colaborativo.

\section{REFERÊNCIAS BIBLIOGRÁFICAS}

ACAMPORA, Ralph. 2005. "Zoos and eyes: contesting captivity and seeking successor practices.". Society and Animals, v.13, n.1: 69-88.

BARATAY, Eric \& HARDOUINFUGIER, Elisabeth. [1998] 2002. Zoo. A History of Zoological Cardens in the West, Londres: Reaktion Books.

BERGER, John. [1977] 2009. Why look at animals? London: Penguin Books.

DAWKINS, Marian. 2004. "Using behavior to assess animal welfare". Animal Welfare, v. 13: 3-7.

DESPRET, Vincianne. 2004. "The body we care for: Figures of anthropo-zoo-genesis". Body \& Society, v. 10, n.2/3: 111-134. 2011. "As ciências da emoção estão impregnadas de política? Catherine Lutz e a questão do gênero das emoções". Fractal: Revista de Psicologia, v. 23, n. 1: 29-42. 2013 a. "From secret agency to interagency", History and Theory, v. 52: 29-44. 2013 b. "Responding bodies and partial affinities in human-animal worlds". Theory, Culture, Society, v.30, n. 7-8: 51-76.

DIGARD, Jean-Pierre. 1988. "Jalons pour une anthropologie de la domestication animale", L'Homme, v. 28, n.108: 27-58.
ESTEBANEZ, Jean. 2010. "Ceux qui sont proches: lês soigneurs au zoo". Sociétés, v. 2, n.108: 47-57. 2008. "Les jardins

zoologiques ou l'exotique a porte de main". Le Globe, n.148: 49-67.

FAVRET-SAADA, Jeanne. [1990] 2005. "Ser afetado". Cadernos de Campo, v.13, n.13: 155-161.

HARAWAY, Donna. 1988. "Situated Knowledges: The Science Question in Feminism and the Privilege of Partial Perspective". Feminist Studies, v.14, n.3: 575-599. 2003. A companion species manifesto: dogs, people, and significant otherness, Chicago: Prickly Paradigm. 2008. When species meet.

Minneapolis: University of Minnesota Press.

HODAK, Caroline. 1999. "Les animaux dans la cité: pour une histoire urbaine de la nature". Cenèses, v. 37: 156-169.

LISPECTOR, Clarice. [1960] 2013. "O Búfalo". In: Laços de família, Rocco: Rio de Janeiro.

MARVIN, Garry. 2008. "L'animal de zoo: Um rôle entre sauvage et domestique". Techniques \& Culture, v.50, n.1: 102-119.

NUNES, Benedito. 2007. "O animal e o primitivo: os Outros de nossa cultura”. História, Ciências, Saúde-Manguinhos, v.14, n 4: 279-290. 1989. O Drama da Linguagem: Uma Leitura de Clarice Lispector. São Paulo: Ática. 
humanos e animais em um zoológico na Amazônia (Belém - PA)

PEREIRA DA SILVA, Matheus. 2019.

"Caminhos Multiespécies de Tratadores e Animais ao Longo do Zoo". REVISTA

FLORESTAN, v. 1: 108-119.

2017. Intimismo interespecífico

entre tratadores e animais no zoo do Bosque.

Belém, TCC, Universidade Federal do Pará.

SILVA, Matheus \& SILVEIRA, Flávio. 2015. Dimensões relacionais de tratadores e animais cativos no zoo do 'Bosque'. In: I Congresso Nacional de Ciências Sociais: desafios da inserção em contextos contemporâneos, 2015, Vitória-ES. Anais do I Conacso I Congresso Nacional de Ciências Sociais. Vitória, 2015. v. 1: 734-746.
SILVEIRA, Flávio da. 2016. “As relações humanas e não-humanas na metrópole amazônica. Estudo etnográfico no Bosque Rodrigues Alves, Belém (PA).", In: BEVILAQUA, Ciméa B.; Vander Velden, Felipe. (Org.). Parentes. vítimas, sujeitos: perspectivas antropológicas sobre relações entre humanos e animais, Ed. Curitiba; São Carlos: EdUFPR; EdUFSCar : 285-308. 2014. "Paisagens do

Bosque Rodrigues Alves, Belém (PA): considerações sobre a conservação do patrimônio urbano no contexto amazônico", Antíteses (Londrina), v. 7: 230-257.

SILVEIRA, Flávio da. \& SILVA, Matheus da. 2015. "Acerca do olhar do outro, ou sobre tratadores e animais em cativeiro - Por uma etnografia no zoo em contexto urbano (Belém - PA)". CADECS, v. 3: 54-74.

Recebido em 07 de maio de 2018. Aceito em 29 de julho de 2019. 